\title{
Evaluation of in vivo migration of chondrocytes from tissue-engineered cartilage that was subcutaneously transplanted in mouse model
}

\author{
Mariko Matsuyama ${ }^{1,2}$, Yuko Fujihara ${ }^{2,3}$, Ryoko Inaki $^{1}$, Satoru Nishizawa ${ }^{4}$, Satoru Nagata ${ }^{5}$, \\ Tsuyoshi Takato ${ }^{1,3}$, Kazuto Hoshi ${ }^{1,2,3^{\star}}$ \\ ${ }^{1}$ Department of Sensory and Motor System Medicine, The University of Tokyo Hospital, Tokyo, Japan; \\ *Corresponding Author: pochi-tky@umin.net \\ ${ }^{2}$ Department of Cartilage \& Bone Regeneration (Fujisoft), Graduate School of Medicine, The University of Tokyo, Tokyo, Japan \\ ${ }^{3}$ Division of Tissue Engineering, The University of Tokyo Hospital, Tokyo, Japan \\ ${ }^{4}$ Translational Research Center, The University of Tokyo Hospital, Tokyo, Japan \\ ${ }^{5}$ NAGATA Microtia and Reconstructive Plastic Surgery Clinic, Toda, Saitama, Japan
}

Received 20 August 2013; revised 20 September 2013; accepted 2 October 2013

Copyright (C) 2013 Mariko Matsuyama et al. This is an open access article distributed under the Creative Commons Attribution License, which permits unrestricted use, distribution, and reproduction in any medium, provided the original work is properly cited.

\section{ABSTRACT}

For regenerative medicine, clarification of in vivo migration of transplanted cells is an important task to secure the safety of transplanted tissue. We had prepared tissue-engineered cartilage consisting of cultured chondrocytes with collagen hydrogel and a biodegradable porous polymer, and we clinically applied it for treatment of craniofacial anomaly. To verify the safety of this tissue-engineered cartilage, we had syngenically transplanted the tissue-engineered cartilage using chondrocytes harvested from EGFP-transgenic mice into subcutaneous pocket of wild type mice, and investigated localizations of transplanted chondrocytes in various organs including cerebrum, lung, liver, spleen, kidney, auricle, gastrocnemius, and femur. After 8 to 24 weeks of the transplantation, accumulation of cartilaginous matrices was observed in tissue-engineered cartilage, while EGFP-positive transplanted chondrocytes were localized in this area. Otherwise, no EGFP was immunohistochemically detected in each organ, suggesting that subcutaneously-transplanted chondrocytes do not migrate to other organs through the circulation. In cartilage tissue engineering using cultured chondrocytes, risk for migration and circulation of transplanted cells seemed negligible, and that ectopic growth of the cells was unlikely to occur, showing that this is safe technique with regard to the in vivo mi- gration of transplanted cells.

Keywords: Cartilage; Tissue Engineering;

Chondrocyte; Migration

\section{INTRODUCTION}

Autologous chondrocyte transplantation has been attracting attention as a treatment of defects and injuries of cartilage tissue, which has poor self-repairing capability [1]. Tissue-engineered cartilage with various properties, such as that prepared by injection of cultured chondrocyte suspension [1] and that gelled by mixing with hydrogel [2]. We developed tissue-engineered cartilage by adding autologous cultured chondrocytes to a porous scaffold made of a biodegradable polymer, poly-L-lactic acid (PLLA) [3], in which collagen hydrogel was used as a mucilage to retain cells within the scaffold [4]. Since this regenerative cartilage tissue has firm hardness and a 3D structure, it is applicable for patients with cartilage deformations and defects associated with craniofacial diseases and traumas. We are using this three-dimensionally tissue-engineered cartilage to treat nasal deformation in a congenital craniofacial anomaly, cleft lip and palate. Since this is a novel clinical technique, its safety should be fully investigated [3].

In the guidelines for safety of medical devices using cultured cells established by the Japanese government, the evaluation of in vivo migration of transplanted cells is included as a safety item. Since it has been reported that bone marrow mesenchymal stem cells, from which chondrocytes are originated, transfer into the circulation after 
transplantation and engraft various organs other than bone marrow [5], the possibility for cultured chondrocytes to enter the circulation or to migrate to other organs cannot be ruled out. Thus, we performed this study to investigate the in vivo migration of cultured chondrocytes after transplantation, and to ensure its safety.

In our previous study, the tissue-engineered cartilage matured 8 weeks after transplantation [6]. At 8 weeks, the transplanted chondrocytes were completely embedded within cartilaginous matrices, which implied that migration of chondrocytes from the transplants to other organs hardly occurred after that time. Thus, we investigated whether transplanted auricular chondrocytes were migrated to other organs by 8 weeks after transplantation. In addition, we examined it also at 24 weeks to confirm long-term safety.

\section{MATERIALS AND METHODS}

Firstly, we collected auricular cartilage from the ears of EGFP-transgenic mice (6-week-old males, $n=3$, Experimental Animal Division RIKEN BioResource Center, Ibaraki, Japan). After sacrifice by anesthesia with somnopentyl at a fatal dose, approximately 15-mm longitudinal incision was made in the parietal skin. The skin was entirely dissected from the incision line to the apex of the auricle. The auricular cartilage tissue was cut immediately before the tympanum and shaken in $0.15 \%$ collagenase solution at $37^{\circ} \mathrm{C}$ for 8 hours [7]. The isolated auricular chondrocytes were seeded at 500,000 cells/well in a 6 -well plastic plate and cultured in $2 \mathrm{~mL}$ of DMEM containing $5 \%$ fetal bovine serum, $5 \mu \mathrm{g} / \mathrm{mL}$ insulin, and $100 \mathrm{ng} / \mathrm{mL}$ fibroblast growth factor (FGF)-2 [8] as the primary culture. Approximately $1 \times 108$ cells were recovered after 2 passages (P2). These $1 \times 108$ cells and 1 $\mathrm{mL}$ of $1 \%$ collagen hydrogel (atelocollagen, Koken, Tokyo, Japan) were mixed on ice for about 10 minutes. The mixture was infiltrated into sterile PLLA porous scaffold $(5 \times 5 \times 3 \mathrm{~mm}, \mathrm{KRI}$, Kyoto, Japan), and gelled in the dish at $37^{\circ} \mathrm{C}$ for 2 hours to avoid drying (Figure 1, 0 wk).

The tissue-engineered cartilage composed of the PLLA/gel/cells $(n=3)$ was transplanted under the dorsal skin in C57BL/6 mice (Nippon Bio-Supp. Center, Tokyo, Japan) under anesthesia with $16 \mu \mathrm{L} /$ animal of somnopentyl (Figure 1, 0 wk). The transplants and eight kinds of target organs (cerebrum, lung, liver, spleen, kidney, auricle, gastrocnemius, and femur) were excised after 8 and 24 weeks, fixed in 4\% paraformaldehyde for one hour, immersed in PBS, and embedded in paraffin. The serial sections with a $5-\mu \mathrm{m}$ thickness were then prepared.

After observation under excitation fluorescence, the sections of samples were subjected to toluidine blue staining, hematoxylin and eosin staining, and immu-

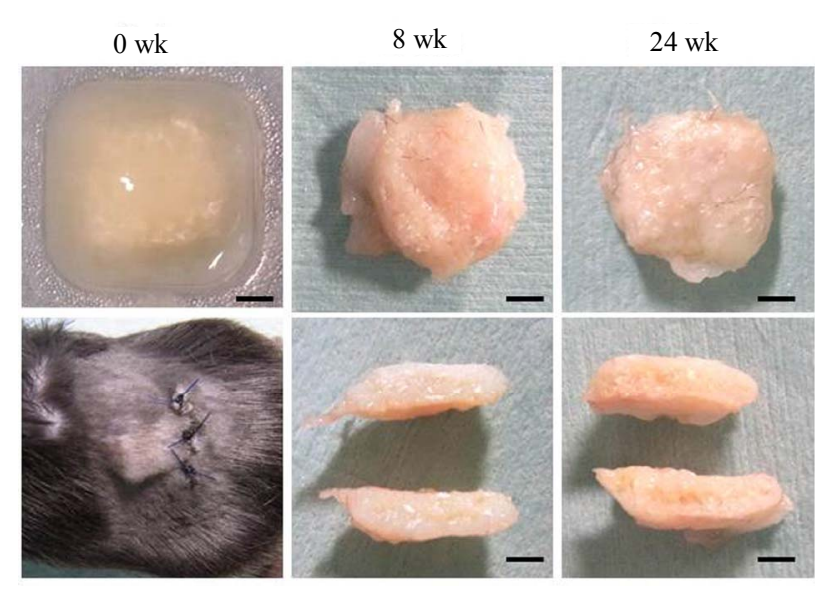

Figure 1. Macroscopic findings of tissue-engineered cartlage. Tisue-engineered cartilage comprised of PLLA scaffold with the mixture of green mouse auricular chondrocytes and atelocollagen was prepared (left top) subcutaneously transplanted into the dorsal region of C57BL/6 mice (left bottom). Whole (top) and half cross-section (bottom) of the transplants, 8 and 24 weeks after transplantation. Scale bar: $1 \mathrm{~mm}$.

nostaining of EGFP. To detect transplant-derived cells, non-serial 10 sections were selected from each organ [9], deparaffinize with xylene, hydrated with stepwise dilutions of ethanol, immersed in PBS, and subjected to immunostaining of EGFP. To activate antigen, the sections were placed in a mixture of $15 \mathrm{~mL}$ of Dako Real Target Retrieval Solution $(\times 10)$ (Dako, Tokyo, Japan) and 135 $\mathrm{mL}$ of $98^{\circ} \mathrm{C}$ hot water, boiled for 15 minutes, kept standing at room temperature for 15 minutes, and immersed in PBS for 5 minutes. This procedure was performed twice. For blocking, 10\% normal goat serum was dripped on the sections and left standing at room temperature for 10 minutes. After removing moisture, the primary antibody, Invitrogen anti-green fluorescent protein rabbit IgG fraction (anti-GFP IgG) (Life Technologies Corporation, Carlsbad, CA, USA), was dripped on the sections (1:1000) and incubated at $37^{\circ} \mathrm{C}$ for 90 minutes. For the control, normal rabbit IgG (SANTA CRUZ BIO- TECHNOLOGY, INC.) was used instead of the primary antibody. After immersing in PBS for 5 minutes twice, the secondary antibody, Anti-IgG, rabbit, goat-poly, Bio- tin (Vector Laboratories, Burlingame, CA, USA), was dripped on the sections $(1: 200)$ and left standing at room temperature for 30 minutes. After immersing in PBS for 5 minutes twice, vectastain ABC (Vector Laboratories, Burlingame, CA, USA) was dripped on the sections and left standing at room temperature for 30 minutes (ABC reaction). After immersing in PBS for 5 minutes twice, the sections were reacted with substrate DAB, and immersed in Milli-Q water. For counter staining, hematoxylin was used. The sections were then dehydrated and sealed.

The organs were similarly collected from 6-week-old 
EGFP-transgenic mice (positive control) and 57BL/6 mice (negative control) and subjected to immunostaining of EGFP. The organ was judged as EGFP-positive when an EGFP-positive cell was present in one or more of the 10 sections [9].

\section{RESULTS}

The tissue-engineered cartilage removed 8 and 24 weeks after transplantation consisted in elastic soft tissue (Figure 1, 8 and 24 wks). The excised transplants were evaluated histologically and immunohistochemically. In toluidine blue staining, metachromasia was noted throughout the transplants at 8 and 24 weeks, suggesting the maturation of regenerative cartilage.

A large area in the transplants was occupied by regenerative cartilage at both 8 and 24 weeks, while the rate was almost similar between them (Figures 2 (a) and (b)). Under 490-nm excitation fluorescence, green fluorescence was noted in the cartilaginous region (Figure 2(c)). In immunohistochemical staining of EGFP, EGFP-positive cells were corresponding to chondrocytes in the cartilaginous region (Figure 2(d)). These findings suggested that chondrocytes in the regenerative cartilage were derived from the cells of the transplants.

The eight target organs were also excised when the transplant was removed at 8 or 24 weeks, and subjected to immunohistochemical staining of EGFP. In theEGFPtransgenic mice, EGFP-positive cells were present in all

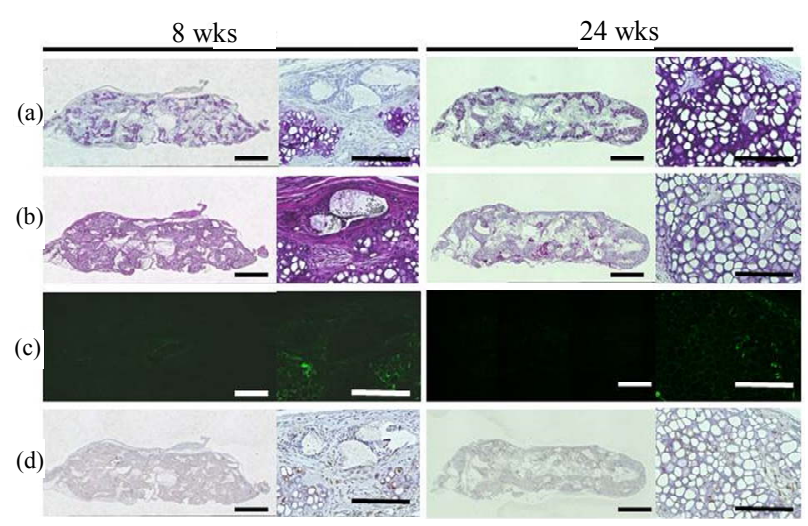

Figure 2. Histological analyses of tissue-engineered cartilage. (a) Toluidine blue staining of tissue-engineered cartilage. Abundant metachromasia was noted 8 and 24 weeks after transplantation, while cartilaginous tissue was extensively observed. (b) Hematoxylin and eosin staining of tissue-engineered cartilage, 8 and 24 weeks after transplantation. Maturation of tissue-engineered cartilage was observed at both weeks. (c) Localization of EGFP-positive chondrocytes was detected under 490-nm excitation fluorescence. (d) Immunohisto- chemical staining of EGFP in tissue-engineered cartilage. The cartilagenous region was constructed only with EGFP-positive transplanted chondrocytes, being consistent with the localization of EGFP-positive cells in C. Scale bar: $1 \mathrm{~mm}$ (low magnification) and $100 \mu \mathrm{m}$ (high magnification). these organs (Figures 3 and 4, EGFP). In the C57BL/6 mice, no positive cells were noted in any of the eight organs (Figures 3 and $\mathbf{4}$, before transplantation). At 8 and 24 weeks after transplantation, no EGFP-positive cells were noted in any of the eight organs (Figures 3 and 4,8 and 4 wks).

The number of positive cells was 0 in any of the eight organs at 8 or 24 weeks after transplantation, showing that chondrocytes in the transplants did not migrate to other organs (Table 1).

\section{DISCUSSION}

We transplanted tissue-engineered cartilage containing EGFP-positive auricular chondrocytes into mice, and histologically confirmed that no chondrocytes migrated to the other organs 8 and 24 weeks after transplantation. As a phenomenon of cell migration between organs, me-

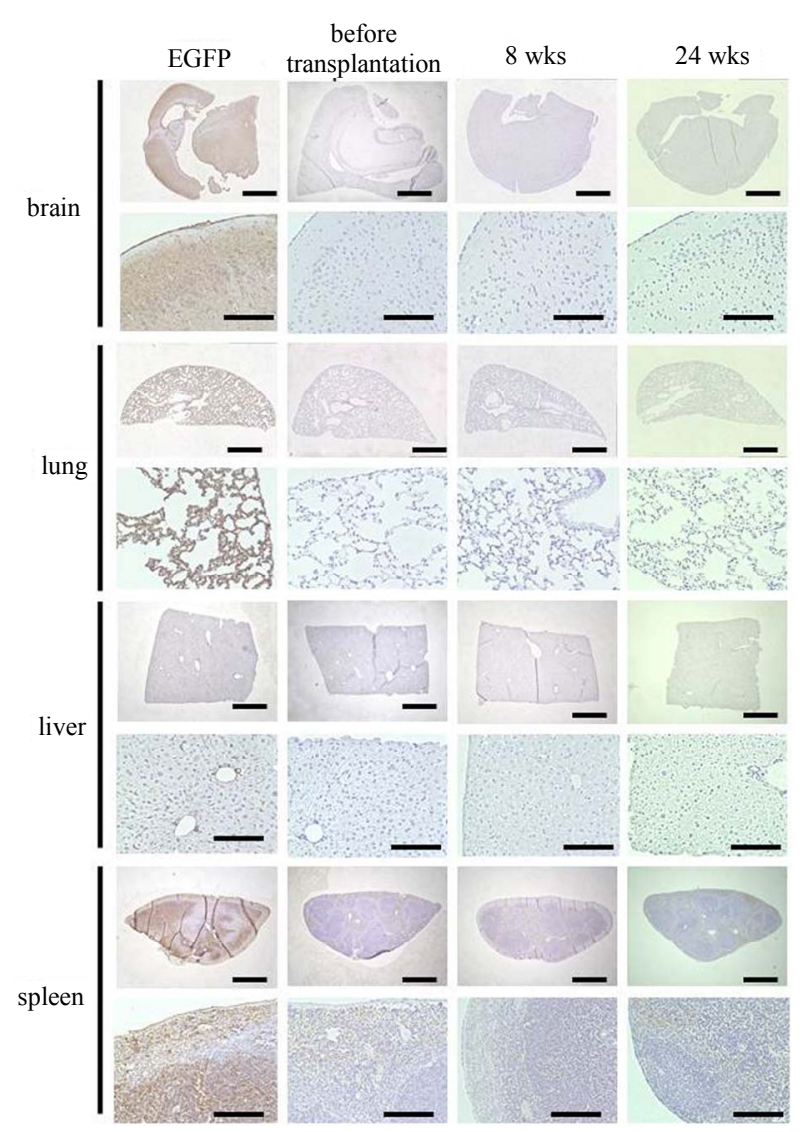

Figure 3. Localization of transplanted chondrocytes in cerebrum, lung, liver, and spleen. Typical photographs of immunohistochemical staining of EGFP in cerebrum, lung, liver, and spleen of C57BL/6 mice were shown before transplantation or at 8 and 24 weeks after transplantation. No EGFP-positive cells were noted in any of the organs. In green mice as the positive control, EGFP-positive cells were noted in all of the organs (EGFP). Staining was performed in 3 animals, and similar results were obtained in all. Scale bar: $1 \mathrm{~mm}$ (low magnification) and $100 \mu \mathrm{m}$ (high magnification). 


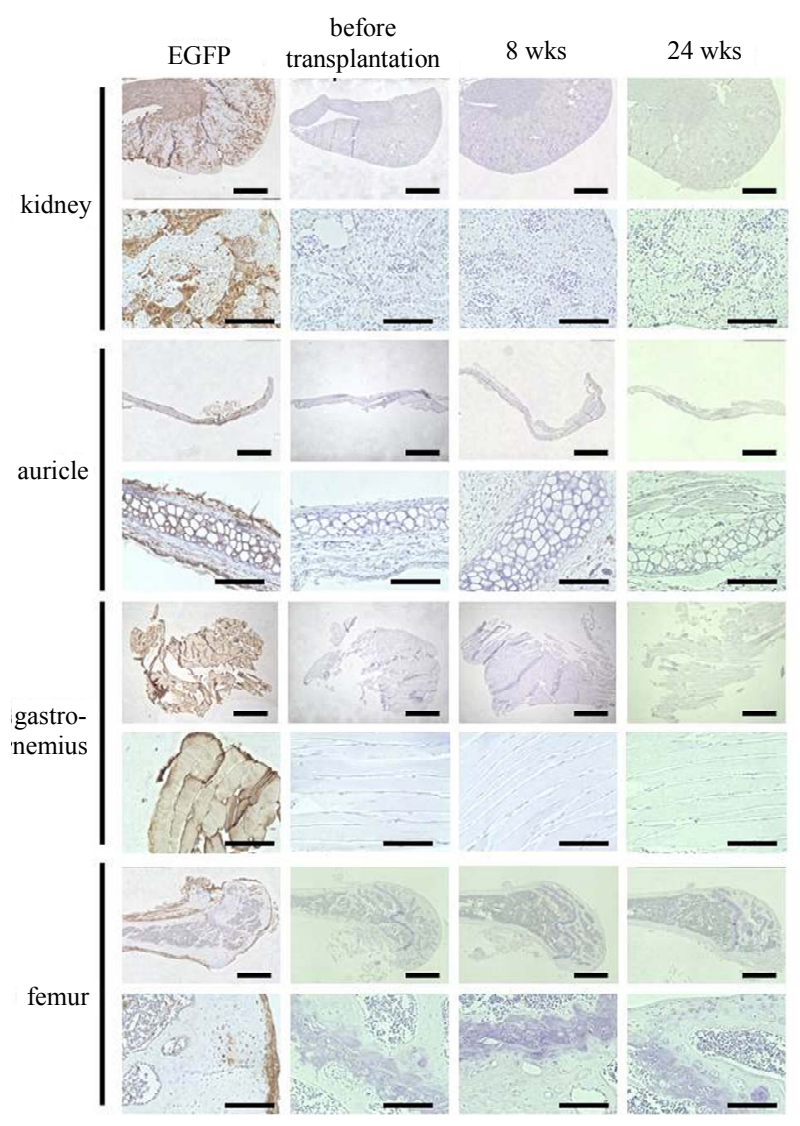

Figure 4. Localization of chondrocytes in kidney, auricle, gastrocnemius, and femur. Typical photographs of immunohistochemical staining of EGFP in kidney, auricle, gastrocnemius, and femur of C57BL/6 mice were shown before transplantation or at 8 and 24 weeks after transplantation. No EGFP-positive cells were noted in any of the organs. In green mice as the positive control, EGFP-positive cells were noted in all of the organs (EGFP). Staining was performed in 3 animals, and similar results were obtained in all. Scale bar: $1 \mathrm{~mm}$ (low magnification) and $100 \mu \mathrm{m}$ (high magnification).

Table 1. Positivity for EGFP in each organ. Ten sections were randomly prepared from each organ of transplanted mice $(\mathrm{n}=$ 3 ), and judged based on the number of EGFP-positive cells as: Grade 1, none; Grade 2, a few; Grade 3, many; and Grade 4, all.

\begin{tabular}{ccccccc}
\hline & \multicolumn{3}{c}{8 wks } & \multicolumn{3}{c}{24 wks } \\
\cline { 2 - 7 } & No.1 & No.2 & No.3 & No.1 & No.2 & No.3 \\
\hline brain & 1 & 1 & 1 & 1 & 1 & 1 \\
lung & 1 & 1 & 1 & 1 & 1 & 1 \\
liver & 1 & 1 & 1 & 1 & 1 & 1 \\
spleen & 1 & 1 & 1 & 1 & 1 & 1 \\
kidney & 1 & 1 & 1 & 1 & 1 & 1 \\
ear flap & 1 & 1 & 1 & 1 & 1 & 1 \\
muscle & 1 & 1 & 1 & 1 & 1 & 1 \\
bone & 1 & 1 & 1 & 1 & 1 & 1 \\
\hline
\end{tabular}

tastasis of cancer is generally known. Metastasis is defined as the spread of cancer cells from the original organ to another one [10]. Various models for metastasis of cancer cells after transplantation have been reported, and cancer metastasis is assumed to be induced by complex interactions of adhesion molecules [11], proteolytic enzymes [12], growth factors [13], vascularization [14], and chemokines [15], as a molecular mechanism.

For example, when U14 squamous cell carcinoma cells were intraperitoneally injected into ICR mice, cervical lymph node metastasis was noted after 15 - 20 days in $53 \%$ of the animals [16]. It has been speculated that lymph node metastasis starts with cancer cell infiltration in the sinus in the marginal region, and then cancer cells invaded the cortex and medulla, destroying the lymph node. One of molecules playing an important role in this tumor formation and metastasis was a matrix metalloproteinase (MMP). The MMPs degrades all types of extracellular matrix. The degradation of extracellular matrix was closely involved in metastasis of tumor cells. Among the MMP family, MMP-2 and -9 were considered to be particularly important factors for metastasis.

As another metastasis model, human lung cancer cells (MDA-MB-231 cells) have been known. When those cells were injected into the left ventricle of nude mice, bone metastasis was noted in $51.8 \%$ after 5 weeks [17]. In that model, many local and growth factors may be secreted from lung cancer cells, secondarily promoting the action of osteoclasts and advancing bone metastasis.

In the above examples, cancer cells were transplanted through routes by which they could readily metastasize to remote organs, such as intraperitoneal and cardiac injections, resulting in metastasis. In contrast, human liver cancer cells (MHCC97-H, MHCC97-L cell lines) caused lung metastasis even through subcutaneous trans- plantation in the dorsal region of nude mice. After $5-6$ weeks of subcutaneous transplantation, $38 \%-58 \%$ of recipient mice showed lung metastasis [18]. As characteristics of this cancer cell, a large amount of transforming growth factor $\beta$ (TGF $\beta$ ) was produced. It was speculated that such excess production of growth factor exceptionally enabled the metastasis of cancer cells, although it rarely occurs in subcutaneous transplantation models.

The cultured chondrocytes we investigated are also capable of producing MMPs [19] or growth factors, such including FGFs and TGF surperfamily [20]. However, the cultured chondrocytes conserve the function that they arrest the cell cycle in response to the stimulation for differentiation [21]. Moreover, we applied subcutaneous transplantation that hardly causes metastasis as the transplantation method. Thus, the cultured chondrocytes in this tissue-engineered cartilage may not cause the migration of cells to other organs.

We also used collagen hydrogel in order to prevent 
leakage of transplanted cells from the scaffold. Generally, tumorigenicity becomes of concern in tissue engineering, if embryonic stem cells or induced pluripotent stem cells are used as cell sources [22]. These kinds of stem cells express adhesion molecules, such as E-cadherin. These molecules are considered to maintain the stem cell properties by forming aggregates [23]. However, in our tissue-engineered cartilage, the cultured chondrocytes were dispersed and mixed with collagen hydrogel, which may inhibit cadherin-mediated cell adhesion and enhanced matrix signals through integrins, promoting the differenttiation [24].

It has been reported that bone marrow-derived mesenchymal stem cells engrafted in other organs, such as cardiac muscle, when the cells were mobilized into the circulation [25]. As the mesenchymal stem cells are origin of chondrocytes, we should discuss the possibility of a similar phenomenon for the cultured chondrocytes. However, the mesenchymal stem cells have very high adhesive ability [26], and are as specific as they fuse with other kind of cells to exhibit pluripotency [27]. As the cultured chondrocytes do not have such prominent adhesiveness, there may be very little possibility that cultured chondrocytes engraft in other organs.

We had prepared the tissue-engineered cartilage using human auricular chondrocytes and clinically applied it for treatment of nasal deformation in cleft lip and palate patients [3]. The risk of migration of transplanted chondrocytes to distant organs should be seriously evaluated, even though there is very little possibility. In this study, no EGFP-positive cells were noted in any of the organs examined, supporting that subcutaneously-transplanted chondrocytes do not migrate to other organs through the circulation. In order to further develop regenerative medicine with cartilage prepared by tissue engineering, we should continue to consider the safety and efficacy of the tissue-engineered constructs from a variety of perspectives.

\section{ACKNOWLEDGEMENTS}

This work was supported by Grants-in-Aid for Scientific Research from the Ministry of Education, Culture, Sports, Science and Technology of Japan (MEXT, No. 24390451, and 25670847) and from the Ministry of Health, Labour and Welfare of Japan (MHLW, No. H24Saisei-Ippan-005).

\section{REFERENCES}

[1] Brittberg, M., Lindahl, A., Nilsson A., Ohlsson, C., Isaksson, O. and Peterson, L. (1994) Treatment of deep cartilage defects in the knee with autologous chondrocyte transplantation. The New England Journal of Medicine, 331, 889-895.

http://dx.doi.org/10.1056/NEJM199410063311401
[2] Ochi, M., Uchio, Y., Kawasaki, K., Wakitani, S. and Iwasa, J. (2002) Transplantation of cartilage-like tissue made by tissue engineering in the treatment of cartilage defects of the knee. Journal of Bone \& Joint Surgery, $\mathbf{8 4}$ 571-578. http://dx.doi.org/10.1302/0301-620X.84B4.11947

[3] Hoshi, K., Fujihara, Y., Asawa, Y., Nishizawa, S., Kanazawa, S., Sakamoto, T., Watanabe, M., Ogasawara, T., Saijo, H., Mori, Y. and Takato, T. (2013) Recent trends of cartilage regenerative medicine and its application to the oral and maxillofacial surgery. Oral Science International, 15, 15-19.

[4] Yamaoka, H., Tanaka, Y., Nishizawa, S., Asawa, Y., Takato, T. and Hoshi, K. (2010) The application of atelocollagen gel in combination with porous scaffolds for cartilage tissue engineering and its suitable condtions. Journal of Biomedical Materials Research Part A, 93, 123-132. http://dx.doi.org/10.1002/jbm.a.32509

[5] Abedin, M., Tintut, Y. and Demer, L.L. (2004) Mesenchymal stem cells and the artery wall. Circulation Research, 95, 671-676.

http://dx.doi.org/10.1161/01.RES.0000143421.27684.12

[6] Asawa, Y., Sakamoto, T., Komura, M., Watanabe, M., Nishizawa, S., Takazawa, Y., Takato, T. and Hoshi, K. (2012) Early stage foreign body reaction against biodegradable polymer scaffolds affects tissue regeneration during the autologous transplantation of tissue-engineered cartilage in the canine model. Cell Transplant, 21, 1431-1442. http://dx.doi.org/10.3727/096368912X640574

[7] Fujihara, Y., Takato, T. and Hoshi, K. (2010) Immunological response to tissue-engineered cartilage derived from auricular chondrocytes and a PLLA scaffold in transgenic mice. Biomaterials, 31, 1227-1234. http://dx.doi.org/10.1016/j.biomaterials.2009.10.053

[8] Takahashi, T., Ogasawara, T., Kishimoto, J., Liu, G., Asato, H., Nakatsuka, T., Uchinuma, E., Nakamura, K., Kawaguchi, H., Chung, U.I., Takato, T. and Hoshi, K. (2005) Synergistic effects of FGF-2 with insulin or IGF-I on the proliferation of human auricular chondrocytes. Cell Transplant, 14, 683-693. http://dx.doi.org/10.3727/000000005783982675

[9] Holleran, J.L., Miller, C.J., Edgehouse, N.L., Pretlow, T.P. and Culp, L.A. (2002) Differential experimental micrometastasis to lung, liver, and bone with lacZ-tagged CWR22R prostate carcinoma cells. Clinical \& Experimental Metastasis, 19, 17-24. http://dx.doi.org/10.1023/A:1013833111207

[10] Nguyen, D.X., Bos, P.D. and Massagué, J. (2009) Metastasis: From dissemination to organ-specific colonization. Nature Reviews Cancer, 9, 274-284. http://dx.doi.org/10.1038/nrc2622

[11] Gao, J.L., Ji, X., He, T.C., Zhang, Q., He, K., Zhao, Y., Chen, S.H. and Lv, G.Y. (2013) Tetrandrine Suppresses Cancer Angiogenesis and Metastasis in 4T1 Tumor Bearing Mice. Evidence-Based Complementary and Alternative Medicine, 2013, 265061. http://dx.doi.org/10.1155/2013/265061

[12] Matsumoto, Y., Zhang, Q., Akita, K., Nakada, H., Hamamura, K., Tsuchida, A., Okajima, T., Furukawa, K., Urano, T. and Furukawa, K. (2013) Trimeric Tn antigen on Syndecan-1 produced by ppGalNAc-T13 enhances 
cancer metastasis via a complex formation with integrin $\alpha 5 \beta 1$ and matrix metalloproteinase 9. Journal of Biological Chemistry, 288, 24264-24276. http://dx.doi.org/10.1074/jbc.M113.455006

[13] Chien, M.H., Lee, L.M., Hsiao, M., Wei, L.H., Chen, C,H., Lai, T.C., Hua, K.T., Chen, M.W., Sun, C.M. and Kuo, M.L. (2013) Inhibition of metastatic potential in breast carcinoma in vivo and in vitro through targeting VEGFRs and FGFRs. Evidence-Based Complementary and Alternative Medicine, 2013, 718380. http://dx.doi.org/10.1155/2013/718380

[14] Huang, Q.B., Ma, X., Zhang, X., Liu, S.W., Ai, Q., Shi, T.P., Zhang, Y., Gao, Y., Fan, Y., Ni, D., Wang, B.J., Li, H.Z. and Zheng, T. (2013) Down-regulated miR-30a in clear cell renal cell carcinoma correlated with tumor hematogenous metastasis by targeting angiogenesis-specific DLL4. PLoS One, 8, e67294. http://dx.doi.org/10.1371/journal.pone.0067294

[15] Yoshimura, T., Howard, O.M., Ito, T., Kuwabara, M., Matsukawa, A., Chen, K., Liu, Y., Liu, M., Oppenheim, J.J. and Wang, J.M. (2013) Monocyte chemoattractant protein-1/CCL2 produced by stromal cells promotes lung metastasis of 4T1 murine breast cancer cells. PLoS One, 8, e58791. http://dx.doi.org/10.1371/journal.pone.0058791

[16] Zhao, X., Pang, L., Qian, Y., Wang, Q., Li, Y., Wu, M., Ouyang, Z., Gao, Z. and Qiu, L. (2013) An animal model of buccal mucosa cancer and cervical lymph node metastasis induced by U14 squamous cell carcinoma cells. Experimental and Therapeutic Medicine, 5, 1083-1088. http://dx.doi.org/10.3892/etm.2013.938

[17] Jeong, J., Lee, K.S., Choi, Y.K., Oh, Y.J. and Lee, H.D. (2011) Preventive effects of zoledronic acid on bone metastasis in mice injected with human breast cancer cells. Journal of Korean Medical Science, 26, 1569-1575. http://dx.doi.org/10.3346/jkms.2011.26.12.1569

[18] Li, G.C., Ye, Q.H., Dong, Q.Z., Ren, N., Jia, H.L. and Qin, L.X. (2012) TGF beta1 and related-Smads contribute to pulmonary metastasis of hepatocellular carcinoma in mice model. Journal of Experimental \& Clinical Cancer Research, 14, 93.

http://dx.doi.org/10.1186/1756-9966-31-93

[19] Asawa, Y., Ogasawara, T., Takahashi, T., Yamaoka, H., Nishizawa, S., Matsudaira, K., Mori, Y., Takato, T. and Hoshi, K. (2009) Aptitude of auricular and nasoseptal chondrocytes cultured under a monolayer or three-dimensional condition for cartilage tissue engineering. Tissue Engineering Part A, 15, 1109-1118. http://dx.doi.org/10.1089/ten.tea.2007.0218

[20] Yamaoka, H., Nishizawa, S., Asawa, Y., Fujihara, Y., Ogasawara, T., Yamaoka, K., Nagata, S., Takato, T. and
Hoshi, K. (2010) Involvement of fibroblast growth factor 18 in dedifferentiation of cultured human chondrocytes. Cell Proliferation, 43, 67-76. http://dx.doi.org/10.1111/j.1365-2184.2009.00655.x

[21] Liu, G., Kawaguchi, H., Ogasawara, T., Asawa, Y., Kishimoto, J., Takahashi, T., Chung, U.I., Yamaoka, H., Asato, H., Naka-mura, K., Takato, T. and Hoshi, K. (2007) Optimal combination of soluble factors for tissue engineering of permanent cartilage from cultured human chondrocytes. Journal of Biological Chemistry, 282, 2040720415. http://dx.doi.org/10.1074/jbc.M608383200

[22] Menendez, S., Camus, S., Herreria, A., Paramonov, I., Morera, L.B., Collado, M., Pekarik, V., Maceda, I., Edel, M., Consiglio, A., Sanchez, A., Li, H., Serrano, M. and Belmonte, J.C. (2012) Increased dosage of tumor suppressors limits the tumorigenicity of iPS cells without affecting their pluripotency. Aging Cell, 11, 41-50. http://dx.doi.org/10.1111/j.1474-9726.2011.00754.x

[23] Chen, T., Yuan, D., Wei, B., Jiang, J., Kang, J., Ling, K., Gu, Y., Li, J., Xiao, L. and Pei. G. (2010) E-cadherin-mediated cell-cell contact is critical for induced pluripotent stem cell generation. Stem Cells, 28, 1315-1325. http://dx.doi.org/10.1002/stem.456

[24] Yamaoka, H., Asato, H., Ogasawara, T., Nishizawa, S., Takahashi, T., Nakatsuka, T., Koshima, I., Nakamura, K., Kawaguchi, H., Chung, U.I., Takato, T. and Hoshi, K. (2006) Cartilage tissue engineering using human auricular chondrocytes embedded in different hydrogel materials. Journal of Biomedical Materials Research Part A, 78, 111. http://dx.doi.org/10.1002/jbm.a.30655

[25] Barbash, I.M., Chouraqui, P., Baron, J., Feinberg, M.S., Etzion, S., Tessone, A., Miller, L., Guetta, E., Zipori, D., Kedes, L.H., Kloner, R.A. and Leor, J. (2003) Systemic delivery of bone marrow-derived mesenchymal stem cells to the infarcted myocardium: feasibility, cell migration, and body distribution. Circulation, 108, 863-868. http://dx.doi.org/10.1161/01.CIR.0000084828.50310.6A

[26] Liu, G., Iwata, K., Ogasawara, T., Watanabe, J., Fukazawa, K., Ishihara, K., Asawa Y., Fujihara, Y., Chung, U.L., Moro, T., Takatori, Y., Takato, T., Nakamura, K., Kawaguchi, H. and Hoshi, K. (2010) Selection of highly osteogenic and chondrogenic cells from bone marrow stromal cells in biocompatible polymer-coated plates. Journal of Biomedical Materials Research Part A, 92, 12731282. http://dx.doi.org/10.1002/jbm.a.32460

[27] Terada, N., Hamazaki, T., Oka, M., Hoki, M., Mastalerz, D.M., Nakano, Y., Meyer, E.M., Morel, L., Petersen, B.E. and Scott, E.W. (2002) Bone marrow cells adopt the phenotype of other cells by spontaneous cell fusion. $\mathrm{Na}$ ture, 416, 542-545. http://dx.doi.org/10.1038/nature730 